\title{
Effect of Cardiogenic Oscillations on Trigger Delay During Pressure Support Ventilation
}

\author{
Glauco M Plens MD, Caio CA Morais PT MSc, Maria A Nakamura PT PhD, \\ Patricia N Souza PT PhD, Marcelo BP Amato MD PhD, Mauro R Tucci MD PhD, and \\ Eduardo LV Costa MD PhD
}

\begin{abstract}
BACKGROUND: Sensitive flow or pressure triggers are usually applied to improve ventilator response time. Conversely, too sensitive triggers can incur risk of auto-triggering, a type of asynchrony in which a breath is triggered without inspiratory muscle activity. A frequent cause of auto-triggering is cardiogenic oscillations, characterized by cyclical variations in pressure and flow waveforms caused by cardiac contractions. Our goal was to test trigger performance and capacity to abolish auto-triggering in $\mathbf{5}$ different ICU ventilators using different simulated levels of cardiogenic oscillations. METHODS: A mechanical breathing simulator was used to test 5 different ICU ventilators' trigger response time and capacity to minimize auto-triggering in conditions with 0 , $0.25,0.5$, and $1 \mathrm{~cm} \mathrm{H}_{2} \mathrm{O}$ cardiogenic oscillation. Each ventilator was evaluated until an ideal trigger was found (the most sensitive that abolished auto-triggering). When the least sensitive flow trigger was unable to avoid auto-triggering, a pressure trigger was used. We compared time delay, airway pressure drop until triggering, and work of breathing before each trigger, all at the ideal trigger level for each cardiogenic oscillation amplitude. We also assessed the proportion of auto-triggered breaths in the whole range of trigger levels tested. RESULTS: Larger cardiogenic oscillations were associated with more frequent auto-triggering. To avoid auto-triggering, less sensitive triggers were required ( +2.51 L/min per $1 \mathrm{~cm} \mathrm{H}_{2} \mathrm{O}$ increase in cardiogenic oscillation; 95\% CI 2.26-2.76, $\left.P<.001\right)$. Time delay increased with larger cardiogenic oscillations, because less sensitive trigger levels were required to abolish auto-triggering (4.79-ms increase per $1 \mathrm{~L} / \mathrm{min}$ increment on flow trigger). CONCLUSIONS: More sensitive triggers led to faster ventilator response, but also to more frequent auto-triggering. To avoid auto-triggering, less sensitive triggers were required, with consequent slower trigger response. To compare trigger performance in a scenario that more closely represents clinical practice, evaluation of the tradeoff between time delay and frequency of autotriggering should be considered. Key words: artificial respiration; mechanical ventilators; interactive ventilatory support; work of breathing; respiratory mechanics; respiratory physiology. [Respir Care 2018;63(7):865-872. @ 2018 Daedalus Enterprises]
\end{abstract}

\section{Introduction}

During assisted breathing, part of the inspiratory muscle effort is spent on triggering the ventilator. Usually, venti-

\footnotetext{
Dr Plens, Mr Morais, Dr Nakamura, Dr Amato, Dr Tucci, and Dr Costa are affiliated with the Divisao de Pneumologia, Instituto do Coracao, Hospital das Clinicas HCFMUSP, Faculdade de Medicina, Universidade de Sao Paulo, Sao Paulo, Brazil. Dr Nery and Dr Costa are affiliated with the Hospital Sírio Libanês, São Paulo, Brazil.

Supplementary material related to this paper is available at http:// www.rcjournal.com.
}

lators have 2 types of triggers: (1) pressure triggering, in which the inspiratory effort must generate a sufficient reduction in airway pressure below the set trigger threshold, commonly between 0.5 and $2.0 \mathrm{~cm} \mathrm{H}_{2} \mathrm{O}$ below PEEP; (2) flow triggering, in which the assisted breath starts when a

\footnotetext{
This study was partially supported by FAPESP (Fundação de Amparo e Pesquisa do Estado de São Paulo). Mr Morais has disclosed a relationship with Magnamed. Dr Amato has disclosed a relationship with Medtronic. Dr Costa has disclosed a relationship with Magnamed. The remaining authors have disclosed no conflicts of interest.
} 
change in the baseline gas flow in the ventilator circuit exceeds a preset value, typically from 1 to $5 \mathrm{~L} / \mathrm{min}$. Flow triggering can be associated with decreased inspiratory work of breathing as compared with pressure triggering, and lower preset trigger values usually lead to faster ventilator response times. ${ }^{1-3}$

Too sensitive triggering, however, can lead to ventilator auto-triggering, a type of asynchrony in which a ventilator breath is triggered in the absence of inspiratory muscle activity. This type of asynchrony occurs in both types of triggering. ${ }^{2}$ Auto-triggering can result in respiratory alkalosis; intrinsic PEEP with cardiovascular instability; barotrauma; or delayed declaration of death in brain-dead patients, prohibiting organ donation; and, during a spontaneous breathing trial to test patient readiness for weaning, it may produce a false impression of a failed test. ${ }^{4-6}$ Potential sources of auto-triggering include correctable causes, such as fluid accumulation in the ventilator circuit or gas leak in the ventilator circuit or around the artificial airway cuff. Other causes, intrinsic to the patient, such as cardiogenic oscillations, cannot be corrected and mandate changes in the trigger threshold setting., ${ }^{4-9}$

Cardiogenic oscillations are cyclical variations in pressure (up to 2-3 $\mathrm{cm} \mathrm{H}_{2} \mathrm{O}$ ) and flow (up to $5.0-6.5 \mathrm{~L} / \mathrm{min}$ ) curves of the ventilator produced by changes in intrathoracic volume caused by cardiac contractions. ${ }^{8,10}$ The trigger performance of the new generation ventilators during pressure support ventilation is variable. The influence of trigger performance on the frequency of auto-triggering caused by cardiogenic oscillations and the changes required in the trigger setting to abolish auto-triggering are subjects that need clarification.

The main objective of this study was to test the trigger performance at the level chosen to minimize auto-triggering caused by cardiogenic oscillations. For this purpose, we tested 5 ICU ventilators during a standard inspiratory effort created by a simulation system with and without cardiogenic oscillations.

\section{Methods}

\section{Spontaneous Breathing Simulation}

We programmed a standard inspiratory effort using the Active Servo Lung 5000 (ASL 5000, IngMar Medical, Pittsburgh, Pennsylvania), a breathing simulator that digitally controls a piston to simulate patient effort and re-

Correspondence: Eduardo LV Costa MD PhD, Universidade de São Paulo, Av. Drive Arnaldo 455, Sala 2144, 2nd floor, São Paulo 01246-903, Brazil. E-mail: eduardoleitecosta@gmail.com.

DOI: $10.4187 /$ respcare.05995

\section{QUICK LOOK}

\section{Current knowledge}

Sensitive flow or pressure triggers are usually applied to improve ventilator response time. Too sensitive triggers can result in auto-triggering, when the ventilator inappropriately senses a patient effort without inspiratory muscle activity. In clinical practice, triggers are usually set at the most sensitive level that does not lead to auto-triggering. Conversely, bench tests of trigger performance commonly compare trigger response times, not taking the frequency of auto-triggering into account.

\section{What this paper contributes to our knowledge}

In a mechanical breathing simulator, we simulated cardiogenic oscillations of various amplitudes added on top of the muscle pressure. The presence of cardiogenic oscillations required less sensitive triggers to avoid auto-triggering, leading to trigger levels that varied for each ventilator tested. Considering the tradeoff between ventilator response time and frequency of auto-triggering, trigger performance tests should include scenarios conducive to auto-triggering, such as the one we described.

spiratory system mechanics. For this study, ASL was set with a pulmonary compliance of $20 \mathrm{~mL} / \mathrm{cm} \mathrm{H}_{2} \mathrm{O}$; airway resistance of $10 \mathrm{~cm} \mathrm{H}_{2} \mathrm{O} / \mathrm{L} / \mathrm{s}$, peak inspiratory effort of $-10 \mathrm{~cm} \mathrm{H}_{2} \mathrm{O}$; breathing frequency of 12 breaths/min; residual capacity of $500 \mathrm{~mL}$. Acquisition was carried out at an environmental temperature of $24^{\circ} \mathrm{C}$ (air-conditioned room), using dry gas from the medical gas pipeline system. Volume measurements were analyzed as measured, without any correction. To simulate cardiogenic oscillations, we also programmed the test lung to generate pressure variations of $0.25,0.5$, and $1 \mathrm{~cm} \mathrm{H}_{2} \mathrm{O}$ at a frequency of $84 / \mathrm{min}$ on top of the muscle pressure curve (Fig. 1). The code for generating the cardiogenic oscillations on top of the muscle pressure curve was written in $\mathrm{R} 3.4 .1^{11}$ and is available in the supplementary materials at http://www. rcjournal.com.

\section{Mechanical Ventilators}

A total of 5 mechanical ventilators were tested: Evita XL (Dräger, Lübeck, Germany), Servo-i (Maquet, Solna, Sweden), Puritan-Benett 840 (Nellcor Puritan-Benett, Pleasanton California), FlexiMag (MagnaMed, São Paulo, Brazil), and Inter X5 (CareFusion, São Paulo, Brazil). Specifications for each ventilator can be found in the supplementary material. 


\section{Cardiogenic Oscillations and Trigger Delay}
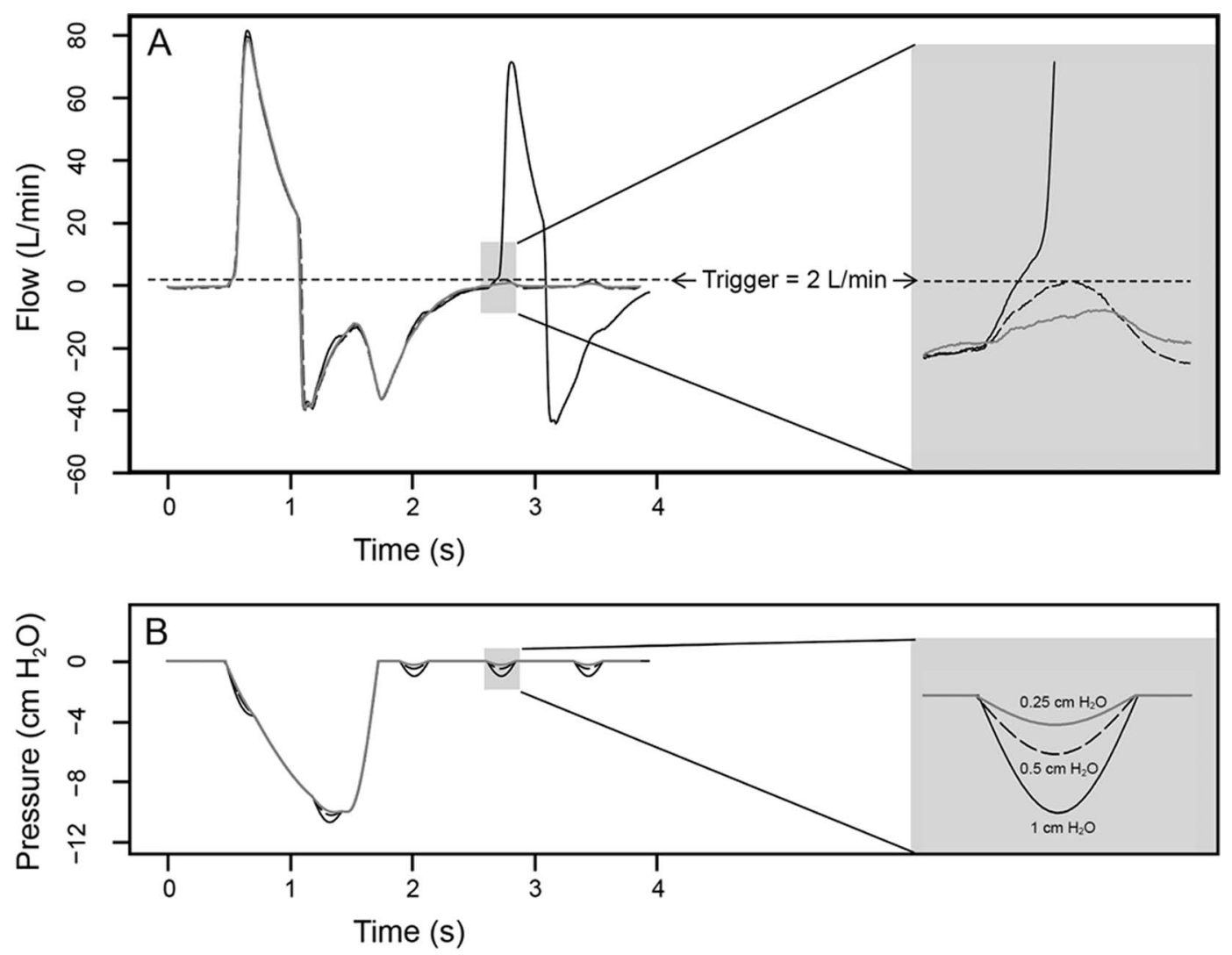

Fig. 1. Representative flow waveforms $(A)$ and muscle pressure (B), illustrating the simulated cardiogenic oscillations of different intensities. Note the effect of cardiogenic oscillations on the flow tracing (shaded areas and magnified views). On the second cycle, the cardiogenic oscillation of $1 \mathrm{~cm} \mathrm{H}_{2} \mathrm{O}$ was enough to exceed the flow-trigger threshold of $2 \mathrm{~L} / \mathrm{min}$, which led to an auto-triggered breath.

In all ventilators, before data acquisition, we ran auto-tests according to recommendations of the manufacturers. The ventilators were connected to the lung simulator using the same standard adult circuit, without a heat and moisture exchanger. All ventilators were set for adult patient size.

Ventilator settings were: pressure controlled continuous spontaneous ventilation, ${ }^{12}$ hereafter called pressure support ventilation, PEEP of $5 \mathrm{~cm} \mathrm{H}_{2} \mathrm{O}$, driving pressure of $15 \mathrm{~cm} \mathrm{H}_{2} \mathrm{O}$, and cycling-off criteria of $25 \%$ for all tested conditions. Inspiratory rise time was set at the maximum possible for each ventilator. None of the ventilators tested had manual adjustment of bias flow.

Each ventilator was evaluated with increasing flow-trigger levels until auto-triggering was abolished for at least 2 consecutive levels. We defined this trigger level as the ideal ventilator trigger. If auto-triggering persisted even at the least sensitive flow-trigger level, we switched to pressure triggering starting at $1 \mathrm{~cm} \mathrm{H}_{2} \mathrm{O}$, which was never associated with auto-triggering. We obtained 20 assisted cycles for each combination of trigger level and cardiogenic oscillation.

\section{Measurements and Analysis}

To assess the ventilators' performance during spontaneous breathing support, the following parameters were calculated: (1) time delay to achieve the lowest inspiratory pressure from the beginning of inspiratory effort (in ms); (2) the fall in airway pressure below PEEP following an inspiratory effort $\left(\Delta \mathrm{P}_{\mathrm{aw}}\right.$, in $\left.\mathrm{cm} \mathrm{H}_{2} \mathrm{O}\right)$; (3) inspiratory work before each trigger $\left(\mathrm{WOB}_{\text {trigger }}\right.$, in $\left.\mathrm{mJ}\right)$; (4) patient's inspiratory work per $\mathrm{L}$ of inspiratory volume $\left(\mathrm{WOB}_{\text {insp }}\right.$, in $\mathrm{mJ} / \mathrm{L}$ ); and (5) the proportion of auto-triggered breaths caused by cardiogenic oscillations. All parameters for each ventilator were directly obtained from the ASL5000 analysis software.

Data from time delay, $\Delta \mathrm{P}_{\mathrm{aw}}, \mathrm{WOB}_{\text {trigger }}$, and $\mathrm{WOB}_{\text {insp }}$ are presented as mean $\pm \mathrm{SD}$ of 15 cycles, excluding the first 3 and the last 2 cycles from the 20 cycles acquired from each simulated condition. Auto-triggering is presented as percentage of cycles and was calculated as the number of auto-triggered cycles divided by the total number of cycles. 


\section{Cardiogenic Oscillations and Trigger Delay}
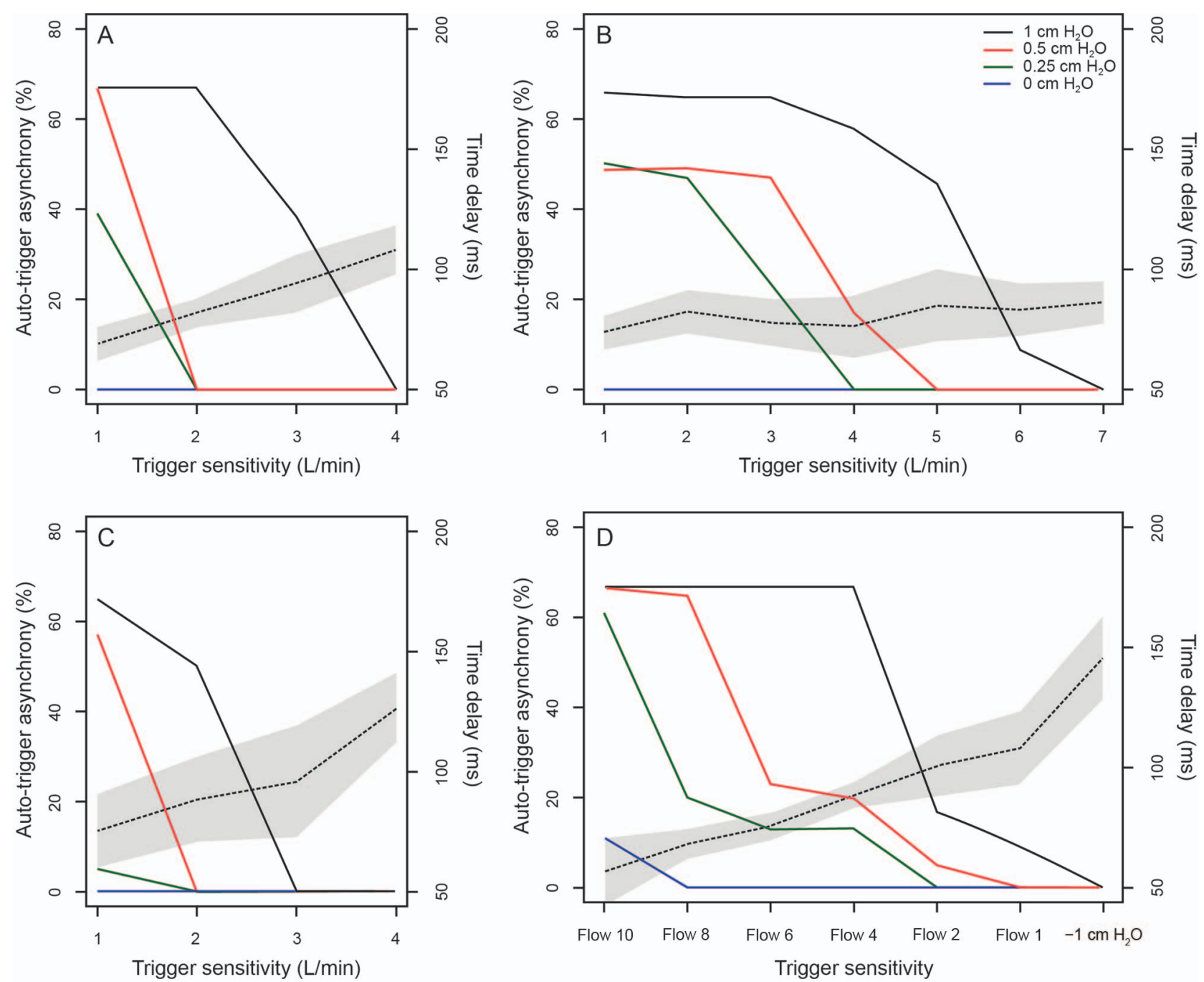

Fig. 2. Ventilator performance according to the different cardiogenic oscillation amplitudes tested from the more sensitive flow trigger to the ideal trigger, which abolished auto-triggering asynchrony. The frequency of auto-triggering (\%) and average \pm SD of time delay (shaded areas) are displayed for each trigger level. The Ix5 is not shown, because auto-triggering never occurred, even at the most sensitive trigger level. A: PB 840, B: Evita XL, C: FlexiMag, D: Servo-i.

We used linear mixed models with random intercepts to analyze the effect of the ideal trigger level on end point time

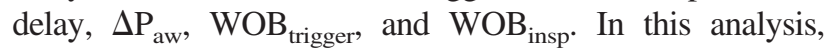
Servo-i values of flow trigger were converted to $\mathrm{L} / \mathrm{min}$. Statistical significance was assumed at a two-tailed $P$ value $<.05$. All analyses were performed with R 3.4.1.11

\section{Results}

Weak $\left(0.25 \mathrm{~cm} \mathrm{H}_{2} \mathrm{O}\right)$ cardiogenic oscillations led on average to inspiratory flows of $0.68 \pm 0.48 \mathrm{~L} / \mathrm{min}$, intermediate $\left(0.5 \mathrm{~cm} \mathrm{H}_{2} \mathrm{O}\right)$ oscillations led to flows of $1.15 \pm 0.71 \mathrm{~L} / \mathrm{min}$, and strong $\left(1.0 \mathrm{~cm} \mathrm{H}_{2} \mathrm{O}\right)$ oscillations led to flows of $1.59 \pm 0.42 \mathrm{~L} / \mathrm{min}$. For a given trigger level, larger cardiogenic oscillations were associated with a higher frequency of auto-triggering (Fig. 2). To avoid auto-triggering, less sensitive trigger settings were required (an average increase of $2.5 \mathrm{~L} / \mathrm{min}$ on the flow trigger per $1 \mathrm{~cm} \mathrm{H}_{2} \mathrm{O}$ increase in cardiogenic oscillation; 95\% CI 2.26-2.76, $P<.001$ ). The trigger performance of all 5 ventilators at the ideal trigger according to the intensity of the cardiogenic oscillations is shown in Table 1.

The ideal trigger varied according to the ventilator tested. Figure 3 shows average curves for each ventilator at the ideal trigger level with $0.5-\mathrm{cm} \mathrm{H}_{2} \mathrm{O}$ cardiogenic oscillations. The faster the ventilator response to breathing effort, the greater was the frequency of auto-triggering compared with slower ventilators for the same flow trigger (see supplementary materials). There was a tradeoff between frequency of auto-triggering and time delay according to each trigger level (Fig. 2). 


\section{Cardiogenic Oscillations and Trigger Delay}

Table 1. Ventilator Performance at the Ideal Trigger Level With Different Intensities of Cardiogenic Oscillations

\begin{tabular}{|c|c|c|c|c|c|c|}
\hline Ventilator & $\begin{array}{c}\text { Cardiogenic } \\
\text { Oscillation }\left(\mathrm{cm} \mathrm{H}_{2} \mathrm{O}\right)\end{array}$ & $\begin{array}{l}\text { Ideal } \\
\text { ventilator } \\
\text { trigger }\end{array}$ & $\mathrm{TD}(\mathrm{ms})$ & $\Delta \mathrm{P}_{\mathrm{aw}}\left(\mathrm{cm} \mathrm{H}_{2} \mathrm{O}\right)$ & $\mathrm{WOB}_{\text {trig }}(\mathrm{mJ})$ & $\mathrm{WOB}_{\text {insp }}(\mathrm{mJ} / \mathrm{L})$ \\
\hline \multirow[t]{4}{*}{ Evita XL } & 0 & $1 \mathrm{~L} / \mathrm{min}$ & $68 \pm 6.5$ & $-0.71 \pm 0.12$ & $0.05 \pm 0.01$ & $474 \pm 6$ \\
\hline & 0.25 & $4 \mathrm{~L} / \mathrm{min}$ & $75 \pm 13.5$ & $-0.69 \pm 0.11$ & $0.12 \pm 0.10$ & $451 \pm 7$ \\
\hline & 0.5 & $5 \mathrm{~L} / \mathrm{min}$ & $79 \pm 14.9$ & $-0.85 \pm 0.07$ & $0.19 \pm 0.17$ & $467 \pm 7$ \\
\hline & 1 & $7 \mathrm{~L} / \mathrm{min}$ & $86 \pm 8.7$ & $-1.25 \pm 0.09$ & $0.28 \pm 0.14$ & $484 \pm 3$ \\
\hline \multirow[t]{4}{*}{ PB 840} & 0 & $1 \mathrm{~L} / \mathrm{min}$ & $68 \pm 0.1$ & $-0.38 \pm 0.01$ & $0.08 \pm 0.00$ & $443 \pm 3$ \\
\hline & 0.25 & $2 \mathrm{~L} / \mathrm{min}$ & $81 \pm 3.1$ & $-0.43 \pm 0.02$ & $0.12 \pm 0.02$ & $454 \pm 4$ \\
\hline & 0.5 & $2 \mathrm{~L} / \mathrm{min}$ & $71 \pm 2.6$ & $-0.32 \pm 0.05$ & $0.23 \pm 0.03$ & $455 \pm 14$ \\
\hline & 1 & $4 \mathrm{~L} / \mathrm{min}$ & $97 \pm 3.1$ & $-0.69 \pm 0.03$ & $0.80 \pm 0.08$ & $472 \pm 2$ \\
\hline \multirow[t]{4}{*}{ Servo-i } & 0 & Flow 6 & $79 \pm 4.1$ & $-0.68 \pm 0.04$ & $0.09 \pm 0.01$ & $504 \pm 4$ \\
\hline & 0.25 & Flow 3 & $97 \pm 6.0$ & $-0.91 \pm 0.07$ & $0.25 \pm 0.05$ & $520 \pm 6$ \\
\hline & 0.5 & Flow 1 & $96 \pm 10.3$ & $-1.2 \pm 0.19$ & $0.35 \pm 0.1$ & $535 \pm 10$ \\
\hline & 1 & $-1 \mathrm{~cm} \mathrm{H}_{2} \mathrm{O}$ & $124 \pm 3.8$ & $-1.96 \pm 0.10$ & $0.86 \pm 0.05$ & $550 \pm 3$ \\
\hline \multirow[t]{4}{*}{ FlexiMag } & 0 & $1 \mathrm{~L} / \mathrm{min}$ & $75 \pm 12.8$ & $-0.68 \pm 0.16$ & $0.08 \pm 0.04$ & $553 \pm 10$ \\
\hline & 0.25 & $2 \mathrm{~L} / \mathrm{min}$ & $81 \pm 19.2$ & $-0.89 \pm 0.29$ & $0.13 \pm 0.07$ & $553 \pm 18$ \\
\hline & 0.5 & $2 \mathrm{~L} / \mathrm{min}$ & $94 \pm 15.5$ & $-1.17 \pm 0.21$ & $0.27 \pm 0.21$ & $568 \pm 12$ \\
\hline & 1 & $3 \mathrm{~L} / \mathrm{min}$ & $85 \pm 7.0$ & $-1.18 \pm 0.13$ & $0.33 \pm 0.10$ & $580 \pm 3$ \\
\hline \multirow[t]{5}{*}{ Ix 5} & 0 & $2 \mathrm{~L} / \mathrm{min}$ & $222 \pm 2.3$ & $-2.24 \pm 0.02$ & $1.47 \pm 0.04$ & $703 \pm 5$ \\
\hline & 0.25 & $2 \mathrm{~L} / \mathrm{min}$ & $190 \pm 2.3$ & $-2.07 \pm 0.02$ & $1.18 \pm 0.04$ & $683 \pm 8$ \\
\hline & 0.5 & $2 \mathrm{~L} / \mathrm{min}$ & $180 \pm 1.6$ & $-2.17 \pm 0.01$ & $1.23 \pm 0.03$ & $687 \pm 6$ \\
\hline & 1 & $2 \mathrm{~L} / \mathrm{min}$ & $160 \pm 1.4$ & $-2.42 \pm 0.01$ & $1.30 \pm 0.02$ & $678 \pm 5$ \\
\hline & & $P<.001^{*}$ & $P<.001 \dagger$ & $P<.001 \ddagger$ & $P<.001 \S$ & $P<.001 \|$ \\
\hline $\begin{array}{l}\text { The ideal venti } \\
* P \text { value for } \mathrm{d} \\
\dagger P \text { value for } \mathrm{d} \\
\ddagger P \text { value for } \mathrm{d} \\
\S P \text { value for } \mathrm{d} \\
\| P \text { value for } \mathrm{d} \\
\mathrm{TD}=\text { time del: } \\
\Delta \mathrm{P}_{\mathrm{aw}}=\text { variati } \\
\mathrm{WOB}_{\text {trigger }}=\mathrm{w} \\
\mathrm{WOB}_{\text {insp }}=\text { ins }\end{array}$ & $\begin{array}{l}\text { gger was the trigger level that } \\
\text { es in ideal trigger levels accord } \\
\text { es in time delay according to th } \\
\text { es in } \Delta \mathrm{P}_{\text {aw }} \text { according to the ide } \\
\text { es in work of breathing before } \\
\text { es in inspiratory work of breath } \\
\text { gger } \\
\text { PEEP to lowest inspiratory air } \\
\text { breathing before the trigger } \\
\text { work of breathing }\end{array}$ & $\begin{array}{l}\text { auto-triggering. } \\
\text { ardiac oscillation. } \\
\text { trigger level. } \\
\text { r level. } \\
\text { er according to the } \\
\text { rding to the ideal t } \\
\text { ssure }\end{array}$ & $\begin{array}{l}\text { igger level. } \\
\text { ivel. }\end{array}$ & & & \\
\hline
\end{tabular}

Time delay was on average $4.79 \mathrm{~ms}$ higher for each 1 $\mathrm{L} / \mathrm{min}$ increment in trigger value (95\% CI 3.36-6.21, $P<.001)$. As a consequence, larger cardiogenic oscillation levels were associated with slower ventilator responses at the ideal trigger (Table 1 and Fig. 2). For less sensitive trigger levels, larger airway pressure drops $\left(\Delta \mathrm{P}_{\mathrm{aw}}\right)$ were observed $\left(-0.11 \mathrm{~cm} \mathrm{H}_{2} \mathrm{O}\right.$ change for each $1 \mathrm{~L} / \mathrm{min}$ increase in trigger level; $95 \% \mathrm{CI}-0.12$ to $-0.09, P<.001$ ) (Table 1). $\mathrm{WOB}_{\text {trigger }}$ also increased with less sensitive flow-trigger values. A $0.09-\mathrm{mJ}$ change was observed for each $1 \mathrm{~L} / \mathrm{min}$ increase in trigger (95\% CI $0.08-0.11$, $P<.001)$. Similarly, $\mathrm{WOB}_{\text {insp }}$ presented an increase of $4.7 \mathrm{~mJ} / \mathrm{L}$ for each $1 \mathrm{~L} / \mathrm{min}$ increase in flow trigger $(95 \% \mathrm{CI}$ 3.6-5.9, $P<.001)$.

\section{Discussion}

We found that the presence of simulated cardiogenic oscillations invariably led to auto-triggering with the most sensitive flow triggers. The flow-trigger level set to min- imize auto-triggering varied among the different ventilators tested, even at fixed values of resistance and compliance of the system and with standardized inspiratory efforts. There was a tradeoff between trigger delay and frequency of auto-triggering.

The trigger level affects the inspiratory work of breathing, and it is therefore common practice to set the trigger level as sensitive as possible. Too sensitive triggers, however, can lead to auto-triggering and significant patientventilator asynchronies. The goal is to set the trigger level at the highest sensitivity that avoids auto-triggering. Testing the performance of different ventilators in this regard can be a challenge, because bench tests usually use simulators that provide pressure and flow waveforms free of extraneous signals, far from representing clinical practice. For the first time, we developed a simulation of cardiogenic oscillations, making it possible to explore the performance of ventilators accounting for this tradeoff between fast trigger response and autotriggering. 

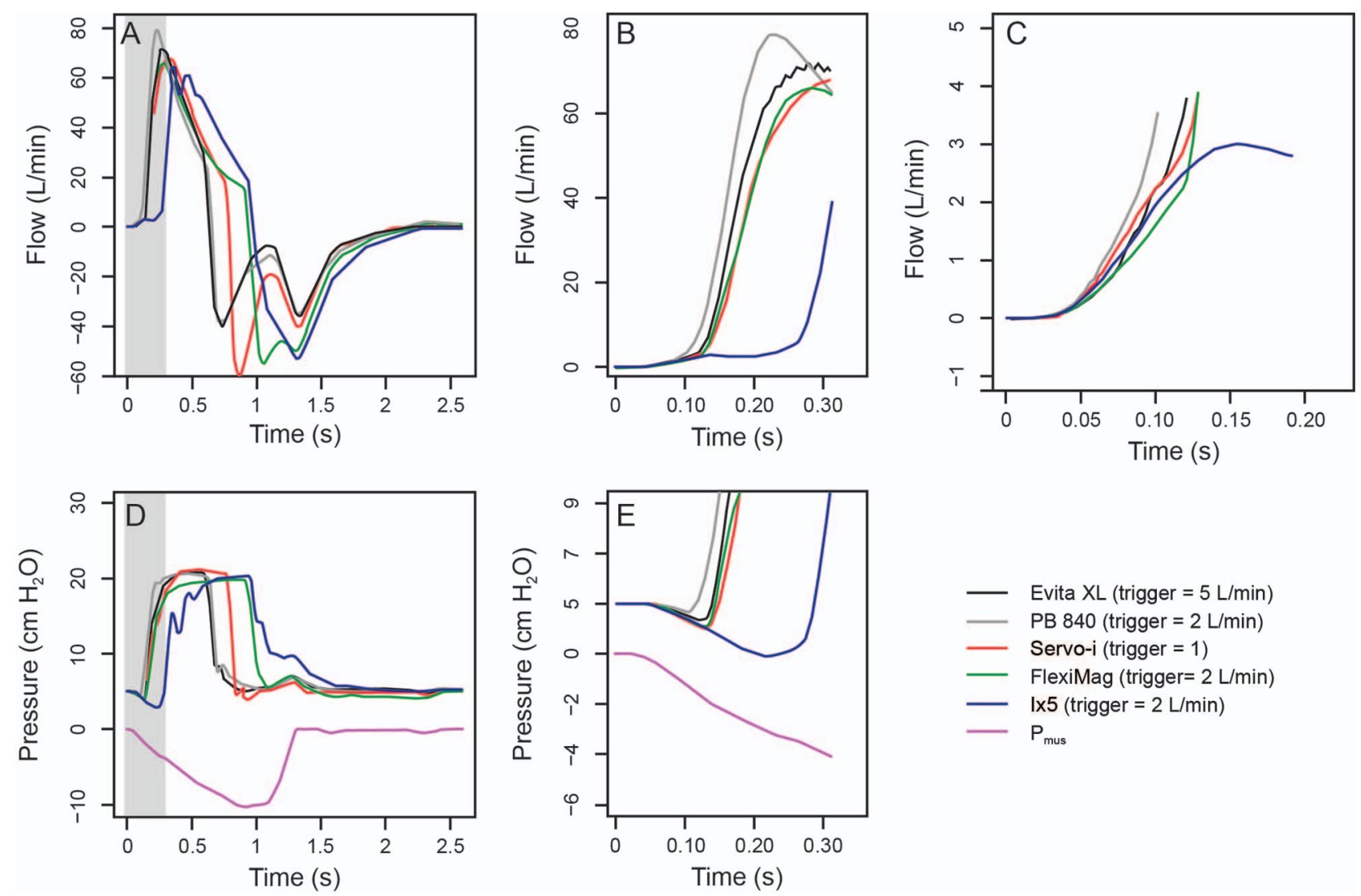

Fig. 3. Average waveforms at the ideal trigger in conditions with cardiogenic oscillation of $0.5 \mathrm{~cm} \mathrm{H}_{2} \mathrm{O}$. Entire cycles of flow $(\mathrm{A})$ and pressure (D) waveforms for each of the 5 ventilators are shown. A zoom into the shaded area shows the difference in inspiratory flows (B) and maximum pressure drop below PEEP $(E)$. In $C$, we show the flow waveforms from the beginning of the inspiratory effort until the lowest airway pressure. The curve for each ventilator was truncated at the lowest airway pressure to represent the time delay.

In our simulations, we found that weak cardiogenic oscillations led on average to inspiratory flows of $0.68 \mathrm{~L} / \mathrm{min}$, intermediate oscillations led to flows of $1.15 \mathrm{~L} / \mathrm{min}$, and strong oscillations led to flows of $1.59 \mathrm{~L} / \mathrm{min}$. These flows are less than the previously described average of $4.7 \mathrm{~L} / \mathrm{min}$ in subjects who had $>5$ auto-trigger events/min. ${ }^{10}$ Other authors described even more pronounced changes in the ventilator waveforms up to $5.0-6.5 \mathrm{~L} / \mathrm{min}$ in the flow tracings, often causing auto-triggering. ${ }^{8,10,13}$ In Figure S1 (see supplementary material), we show an example of the magnitude of cardiogenic oscillations in a patient with ARDS. We decided to simulate weaker cardiogenic oscillations, because in this study we set out to explore the whole range of trigger values, including the most sensitive ones.

Cardiogenic oscillations occur in up to one fifth of those receiving mechanical ventilation, as shown in a prospective cohort of postoperative subjects. ${ }^{10}$ They can be considered a special case of auto-triggering, because, being intrinsic to the patient, they are usually solved by adjusting the trigger level to less sensitive settings as opposed to correcting the underlying cause. Our findings suggest that this ideal trigger level results in a slower ventilator response and increased work of breathing, although the impact was small in most ventilators tested. Patients at increased risk include those with hyperdynamic cardiovascular state (high stroke volume) and low inspiratory drive and breathing frequency, in whom cyclical variation of intrathoracic volume caused by cardiac contraction produces greater oscillation in pressure and flow waveforms of the ventilator. $7,8,10$

The fastest ventilators showed time delays consistently $<100 \mathrm{~ms}$ with all levels of cardiogenic oscillations. Our findings agree with the values without cardiogenic oscillations in previous studies that tested 3 of the ventilators evaluated in our study. ${ }^{14-16}$ The levels of flow or pressure trigger that abolished auto-triggering (ideal trigger level) observed for the different cardiac oscillations values also are in agreement with other studies. ${ }^{6,13} \mathrm{We}$ found that at least one significant component of the ventilator response time was a faster inspiratory flow change rate before the trigger when compared with the slower ventilators (Fig. 4). This was accompanied by a less intense drop in pressure below the PEEP level even before the trigger occurred. This finding is probably a consequence of a more aggressive control of PEEP. With the start of the inspira- 


\section{Cardiogenic Oscillations and Trigger Delay}

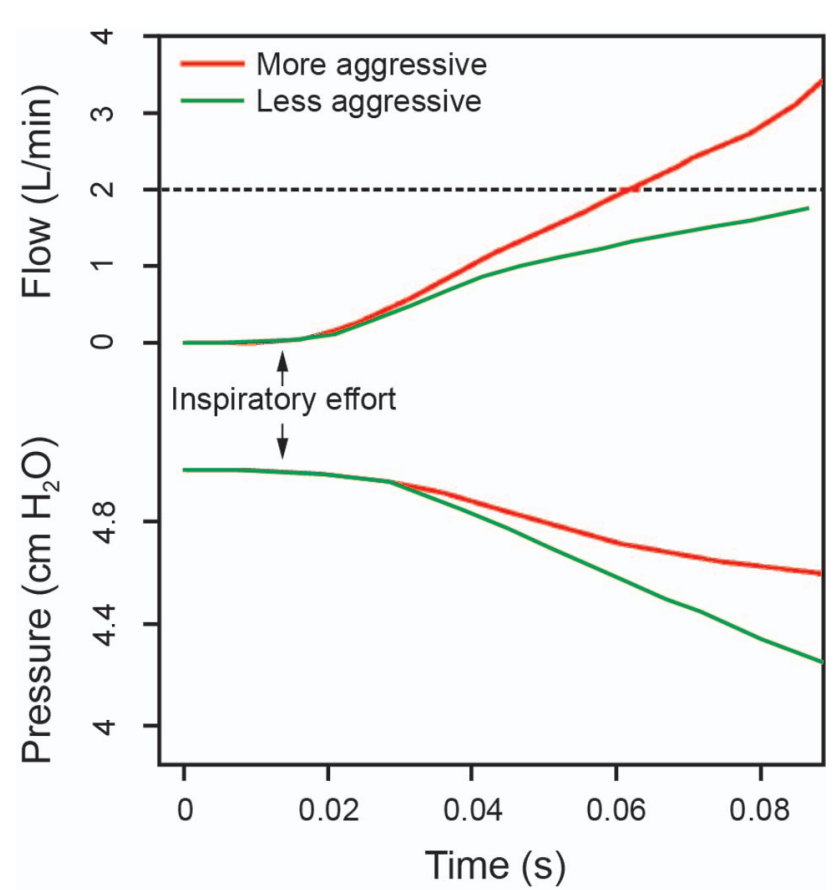

Fig. 4. Representative waveforms of flow (top) and pressure (bottom) of 2 different ventilators to illustrate the importance of the control of PEEP on trigger delay. With the start of the inspiratory effort (arrows), proximal airway pressure will tend to fall, and the more aggressive the control of PEEP is, the more the expiratory valve will close, diverting the bias flow to the patient. As a consequence, the pressure drop below PEEP will be less, and the flow will increase faster in ventilators with more aggressive control of PEEP. Note that the 2 ventilators will reach a fixed trigger level of $2 \mathrm{~L} / \mathrm{min}$, for example, at significantly different time points.

tory effort, proximal airway pressure will tend to fall, and the more aggressive the control of PEEP is, the more the expiratory valve will close, causing the bias flow to be diverted to the patient and essentially functioning as an effort amplifier. This amplification, however, also magnifies other unwanted signals, such as those caused by cardiac oscillations and secretions, potentially leading to auto-triggering. This was probably the mechanism through which the fastest ventilators led more frequently to autotriggering at similar flow-trigger levels as compared with the other ventilators.

Our study has several limitations. First, the study was not conducted in patients. Our choice of a bench study using a simulator allowed precise control of muscle effort and of the intensity of the simulated cardiogenic oscillations, facilitating the comparison of the trigger performance with different settings and on different ventilators. The choice of using a simulator of the respiratory system, however, implies losing biological variability intrinsic to clinical practice, and it is only an approximation of patients' physiology. Second, we only tested one combination of compliance and resistance of the respiratory system, simulating an ARDS patient with severely deranged lung mechanics, a scenario in which trigger delay tends to be lower than in patients with normal lung mechanics or with obstructive lung disease. . $^{3,14,16}$ We performed additional tests in one ventilator (Servo-i) with different compliance settings, and no significant changes were observed in the effect of cardiogenic oscillations on airway pressure, flow, or trigger performance (see supplementary material). The drop in pressure below PEEP is also dependent on the lung model settings, on ventilator settings, and on the level of effort, which were all kept constant. Other settings would probably lead to different estimates of time delays and pressure drops below PEEP. Third, all tests were performed with the fastest inspiratory rise time of each ventilator. Short inspiratory rise time also reduces time delay to achieve the lowest inspiratory pressure, trigger work of breathing, and patient inspiratory work of breathing. ${ }^{17}$ Finally, we only tested pressure support ventilation, because we wanted to represent a condition in which all breaths were triggered by the patient (or auto-triggered). Our results cannot be directly extrapolated to other assisted modes.

\section{Clinical Implications}

Auto-triggering is frequent in some conditions, being present in $>20 \%$ of mechanically ventilated patients in some studies. ${ }^{6,8,10,13}$ Cardiogenic auto-triggering is treated by increasing the flow-trigger level or changing to pressure triggering. ${ }^{6,10,13}$ The simulation of a more realistic scenario with cardiogenic oscillations during spontaneous breathing can increase the knowledge of the best settings for each ventilator to correct this asynchrony, help manufacturers improve the triggering function of the ventilators, and help develop better tools for automatic detection of this type of asynchrony.

\section{Conclusions}

Using a model to simulate cardiogenic oscillations, we were able to assess the trigger performance in a scenario that more closely reproduces clinical practice. We showed that auto-triggering was frequent and required adjustments in trigger settings according to the intensity of cardiogenic oscillations, with a tradeoff between controlling auto-trigger asynchrony and losing trigger response velocity. This study suggests that trigger performance studies should evaluate not only time delay, but also the ventilators' capacity to avoid auto-triggering.

\section{REFERENCES}

1. Aslanian P, El Atrous S, Isabey D, Valente E, Corsi D, Harf A, et al. Effects of flow triggering on breathing effort during partial ventilatory support. Am J Respir Crit Care Med 1998;157(1):135-143. 


\section{Cardiogenic Oscillations and Trigger Delay}

2. Hill LL, Pearl RG. Flow triggering, pressure triggering, and autotriggering during mechanical ventilation (editorial). Crit Care Med 2000;28(2):579-581.

3. Ranieri VM, Mascia L, Petruzzelli V, Bruno F, Brienza A, Giuliani $\mathrm{R}$. Inspiratory effort and measurement of dynamic intrinsic PEEP in COPD patients: effects of ventilator triggering systems. Intensive Care Med 1995;21(11):896-903.

4. Branson RD, Blakeman TC, Robinson BR. Asynchrony and dyspnea. Respir Care 2013;58(6):973-989.

5. Kondili E, Prinianakis G, Georgopoulos D. Patient-ventilator interaction. Br J Anaesth 2003;91(1):106-119.

6. Shoham AB, Patel B, Arabia FA, Murray MJ. Mechanical ventilation and the total artificial heart: optimal ventilator trigger to avoid post-operative autocycling: a case series and literature review. J Cardiothorac Surg 2010;5:39.

7. Kondili E, Xirouchaki N, Georgopoulos D. Modulation and treatment of patient-ventilator dyssynchrony. Curr Opin Crit Care 2007; 13(1):84-89.

8. Arbour R. Cardiogenic oscillation and ventilator autotriggering in brain-dead patients: a case series. Am J Crit Care 2009;18(5):496, 488-495.

9. Campbell RS, Branson RD, Johannigman JA, Davis K, Jr. Erratic ventilator triggering during neuromuscular blockade. Respir Care 1997;42(11):1048-1056.

10. Imanaka H, Nishimura M, Takeuchi M, Kimball WR, Yahagi N, Kumon K. Autotriggering caused by cardiogenic oscillation during flow-triggered mechanical ventilation. Crit Care Med 2000;28(2): 402-407.

11. R Core Team. R: a language and environment for statistical computing. Vienna, Austria: R Foundation for Statistical Computing; 2017. http://www.R-project.org/.

12. Chatburn RL, El-Khatib M, Mireles-Cabodevila E. A taxonomy for mechanical ventilation: 10 fundamental maxims. Respir Care 2014; 59(11):1747-1763.

13. Ou CY, Yang SC, Chen CW. Influence of different flow-triggering levels on the breathing effort of mechanically ventilated patients. Minerva Anestesiol 2012;78(9):996-1004.

14. Ferreira JC, Chipman DW, Kacmarek RM. Trigger performance of mid-level ICU mechanical ventilators during assisted ventilation: a bench study. Intensive Care Med 2008;34(9):1669-1675.

15. Thille AW, Lyazidi A, Richard JC, Galia F, Brochard L. A bench study of intensive-care-unit ventilators: new versus old and turbinebased versus compressed gas-based ventilators. Intensive Care Med 2009;35(8):1368-1376.

16. Williams K, Hinojosa-Kurtzberg M, Parthasarathy S. Control of breathing during mechanical ventilation: who is the boss? Respir Care 2011;56(2):127-136; discussion 136-139.

17. Murata S, Yokoyama K, Sakamoto Y, Yamashita K, Oto J, Imanaka $\mathrm{H}$, Nishimura M. Effects of inspiratory rise time on triggering work load during pressure-support ventilation: a lung model study. Respir Care 2010;55(7):878-884.

This article is approved for Continuing Respiratory Care Education credit. For information and to obtain your CRCE

(free to AARC members) visit www.rcjournal.com

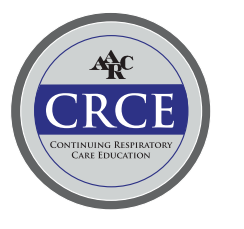

